\title{
Transgender Marriage and the Legal Obligation to Disclose Gender History
}

\author{
Alex Sharpe*
}

Section 12 of the Matrimonial Causes Act 1973 as amended by the Gender Recognition Act 2004 requires transgender people to disclose their 'gender history' to the other party to a marriage prior to the marriage ceremony. Failure to do so enables the other party to exit the relationship through nullity proceedings. This article argues that this provision is discriminatory and encroaches on the right to privacy, breaching Articles 14 and 8 of the European Convention on Human Rights. It challenges the idea, implicit in the provision, that non-disclosure of gender history is unethical or fraudulent. Crucially, the article considers and rejects the claim that discrimination against and encroachments on the privacy of transgender people are justified because inadvertent sexual congress with a transgender person is potentially harmful. Finally, if a consent-based right to know exists, it argues that it ought to be trumped by considerations of justice, legal consistency and public policy.

Do not ask me who I am and do not ask me to remain the same: Leave it to our bureaucrats and our police to see that our papers are in order. ${ }^{1}$

\section{INTRODUCTION}

This article aims to interrogate a specific legal obligation placed on transgender people ${ }^{2}$ intending to marry or enter into a civil partnership in the UK. By virtue of the Gender Recognition Act 2004 (GRA) transgender persons who comply with particular medico-legal conditions are entitled to have their'acquired' gender status legally recognised including for the purposes of marriage. ${ }^{3}$ However, and while the legislation emphasises the comprehensiveness of legal recognition, it is

* Professor of Law at Keele University. I would like to thank Les Moran and Angus Dawson for reading through drafts of this article, for their constructive comments and for their generosity. I would also like to thank the two anonymous referees for the Modern Law Review whose careful readings of the article and considered comments have been particularly helpful.

1 M. Foucault, The Archaeology of Knowledge (New York: Pantheon Books, A. M. Sheridan Smith tr, 1972) 17.

2 For a discussion of trans terminology see L. Feinberg, Transgender Liberation: A Movement Whose Time has Come (New York:WorldView Forum, 1992); K. Bornstein, Gender Outlaw: On Men, Women, and the Rest of Us (New York: Routledge, 1994); and R. A. Wilchins, Read My lips: Sexual Subversion and the End of Gender (Ithaca, New York: Firebrand Books, 1997).

3 Full recognition under the GRA requires transgender applicants to be at least 18 years of age at the time of applying for a Gender Recognition Certificate (GRC) (s 1); to have been diagnosed as 'having or having had gender dysphoria' (s 2(a)); to have lived in the 'new' gender for a period of 2 years (the so-called 'Real Life Test') (s 2(b)); to sign an affidavit stating an intention to live permanently in the 'new' gender 'until death' (s 2(c)); and if previously married, to have divorced (s (3)). Recognition does not require that an applicant has undergone any surgical procedures or taken hormones. 
clear that limits are set. This article is concerned with one particular limit and its implications. Through an amendment to the Matrimonial Causes Act 1973 (MCA), legally recognised transgender people are, in order to avoid nullity proceedings, required to disclose particular facts prior to any marriage or civil partnership ceremony. ${ }^{4}$ The facts that are required to be disclosed pertain to a transgender person's gender history. What must be rendered is an autobiographical account of a gendered life prior to legal recognition of 'acquired' gender status. Failure to do so enables the other party to seek an annulment of the marriage or civil partnership and therefore accelerated exit from the relationship.

The reader might wonder why an analysis of this specific legal obligation placed on transgender people matters. Indeed, a provision enabling early exit from a marriage, rather than leaving the parties to the law of divorce, might be viewed as desirable. That is to say, once a marriage relationship has broken down, good policy reasons for keeping the marriage alive legally might be considered wanting. However, I am not concerned with this issue here. Rather, this article will contend that the enactment of the gender history ground matters because it impacts negatively on transgender people in a number of ways. First, implicit in the creation of the gender history ground is the legal and broader cultural assumption that non-disclosure of gender history to a prospective marriage partner constitutes some form of harm. This assumption will be challenged. Second, the gender history ground singles out gender as the slice of subjectivity in relation to which disclosure of historical 'facts' must be made. It is not entirely clear why gender is singled out. There are no corresponding legal obligations in the MCA pertaining to, for example, race, disability or sexuality. Moreover, and significantly, the gender history ground does not apply to all persons intending to marry. Rather, it is confined to transgender people as a specific class. That is to say, it is only transgender people who are required to disclose their gender history. In this respect, the gender history ground appears to be discriminatory and therefore in conflict with Article 14 of the European Convention on Human Rights.

Third, the requirement to disclose gender history constitutes a significant and illegitimate invasion of privacy and therefore of personal autonomy. In this respect, it conflicts with Article 8 of the European Convention on Human Rights, which guarantees the right to respect for private and family life. Fourth, it is necessary to challenge the idea that non-disclosure of gender history is in some way unethical or fraudulent. In this respect, and in particular, the article will

4 GRA, s 11 gives effect to schedule 4 to the Act. Crucially, paragraph 5 of schedule 4 amends the MCA, s 12 to add a new ground for rendering a marriage voidable, namely:

(h) That the respondent is a person whose gender at the time of the marriage had become the acquired gender under the Gender Recognition Act 2004.

Paragraph 42 of the Explanatory Notes to the Act provides further detail as to how this section is to operate. Thus where:

At the time of the marriage one party to the marriage did not know that the other was previously of another gender, the former may seek to annul the marriage.

A provision pertaining to non-disclosure of gender history is also present in the Civil Partnership Act 2004. Thus a civil partnership will be voidable where the respondent had obtained a GRC (s 50(e)) prior to the ceremony and the petitioner was unaware of this fact (s 51(6)). 
consider how law constructs 'truth' around the facts it demands be disclosed. ${ }^{5}$ While these types of detriment can have practical effects, my central concern about the gender history provision operates at the discursive or symbolic level. This is because the provision represents transgender people as sexually harmful, gender ambiguous and deceptive. Sexually harmful: because inadvertent sexual contact with a transgender person is scripted as harmful. Gender ambiguous: because the gender history ground implies some 'truth' about (trans)gender that is inconsistent both with the fact of legal recognition and the prior gender experiences of many transgender people. Deceptive: because this is precisely what non-disclosure is presumed to be. These claims need to be repudiated.

In taking up this challenge the article will consider and reject arguments that can be offered in defence of the gender history provision. As we will see, the main argument lies in the contention that gender history is a fundamental or material fact that a non-transgender party to a marriage has a right to know. This supposed informational right, which is implied by the existence of the gender history provision, is based on the claim that in the absence of such information consent fails. In dealing with these claims, the notion that gender history is a fundamental or material fact that the other party to the marriage ought to know will be contested. However, if gender history were to be considered a material fact it will be argued that a consent based right to know ought to be trumped by considerations of justice, legal consistency and public policy. Before detailing the ways in which the gender history provision is discriminatory and an illegitimate encroachment on privacy, and before advancing an argument that resists the coupling of non-disclosure with unethical conduct, the article will first consider the concept of harm. This is because it is precisely a legal assumption regarding harm, whether rendered explicit or remaining implicit, that is used to justify the provision. Moreover, it is precisely an assumption about harm that is likely to be used to justify both discrimination and encroachments on privacy as well as the characterisation of non-disclosure as unethical.

\section{NON-DISCLOSURE OF GENDER HISTORY AND THE ASSUMPTION OF HARM}

The enactment of the gender history provision appears to be based on an assumption that in the absence of disclosure some type of harm may arise. There appear to be only two possible explanations for a conclusion of harm. First, non-disclosure of gender history may have an impact on the procreative desires of the other party to the marriage. Having children, and indeed one's own genetic children, is an important aspect of marriage for many people. However, any attempt to justify the gender history ground through an appeal to considerations of procreation is highly suspect. If this were a motivating concern law might require disclosure not of gender history but of reproductive status. Moreover, there are many women and men who are infertile and failure to disclose this

5 While beyond the scope of this article, non-compliance with the gender history provision may also lead to a finding of inequitable conduct barring ancillary relief under the MCA, s 25(2)(g). 
fact does not assume legal significance either in relation to the validity of a marriage or its termination.

The other and more convincing explanation for the introduction of the gender history ground lies in the legal view that the other party to the marriage might not want to marry a person, and let us be honest about it, have sexual intercourse with her, if made aware of her (trans)gender history. In other words, and as Lowe and Douglas contend, the gender history provision apparently finds its rationale and justification in the potential for 'mistake' over gender identity. ${ }^{6}$ The claim here is that a non-transgender person has a right to information that is 'material' to making a decision regarding marriage and sexual congress. This supposed right is based on the notion that in the absence of such information consent fails. Therefore the justification of the gender history ground proves to be based on two claims. First, gender history is a material fact that the other party to a marriage ought to know if their consent is to be valid. Second, and implicitly, there are no other considerations that serve to displace or override this right. Both these claims are demonstrably false. Before considering each, the reader should appreciate that this assertion of a right to know is based on an assumption of harm. While the gender history provision is clearly framed in terms of marriage, not sex, and while marriage is not reducible to sexual intercourse, it is, primarily, concern over inadvertent sexual congress with transgender people that animates the provision. It is this possibility that clearly concerned the parliament and more generally the courts. ${ }^{7}$ It is this conception of harm that the article will challenge.

The claim that gender history ought to be disclosed in the marriage context because it is a fundamental or material fact that goes to the question of consent, and therefore autonomy, is easily understood. Moreover, it almost certainly enjoys considerable weight in normative terms. The argument is perhaps put most forcefully by Herring, albeit with a different emphasis, and albeit in the context of rape where the question of consent also looms. The issue of consent in sexual contexts, is perhaps, especially relevant given that the gender history ground is animated by legal anxiety over the possibility of sexual congress. While recognising that total transparency would place an undue burden on individuals, Herring insists that, if consent is to be valid, facts must be disclosed where considered 'material' by the other party. ${ }^{8}$ Thus, for Herring, whether a fact is material or not depends, not on some general view, but on the subjective viewpoint of the other party. Yet, in the transgender context, this distinction between subjective and objective understandings of what constitutes a material

6 N. Lowe and G. Douglas, Bromley's Family Law (Oxford: Oxford University Press, 10 ${ }^{\text {th }}$ ed, 2006) 90.

7 See notes 25-32 below. Moreover, it is precisely heterosexual intercourse and therefore the possibility of procreation that explains why gender actually matters in the context of marriage. Of course, it might be claimed that non-disclosure of gender history produces harm even where a marriage relationship remains non-sexual. The characterisation of inadvertent sexual congress as harmful puts the case for harm at its strongest through invoking the right to sexual integrity. Accordingly, it is this claim of harm that the article will challenge. In any event, it is contended that, irrespective of sexual congress, feelings of disgust and/or revulsion occasioned by knowledge of gender history fail to meet a threshold of harm sufficient to justify state intervention against transgender people (J.S. Mill, On Liberty (London: Longman, 1998).

8 J. Herring, 'Mistaken Sex' (2005) Crim LR 511-524, 523. 
fact unravels, at least to the extent that it has any impact on the question of disclosure. Thus he asks: 'would a trans-person be required to reveal their bodily history to their partners in case they would not consent to sexual relations if they knew. If so, would that be an improper invasion of the rights of privacy of a trans-person?' His answer: privacy rights 'must be subservient to the right to sexual integrity of their partner. ${ }^{10}$

The difficulty here is evident in the way Herring poses the question. In his transgender scenario we do not know the viewpoint of the non-transgender party. Moreover, this is, perhaps, likely to be typical. Disclosure must take place precisely because of this uncertainty. Of course, Herring will say that a fact is not material if this subsequently proves to be the viewpoint of the other party. However, by then, disclosure may, and is expected to, have occurred. In other words, the obligation to disclose arises because of the possibility, not the actuality, of non-consent. This is clear from the gender history provision, and it is also clear from Herring's argument given his emphasis on the need to disclose 'in case [the other party] would not consent if they knew.' It is precisely because of this danger that Herring views privacy rights as being subservient to the right to sexual integrity. The fact that gender history may subsequently prove to be non-material to the other party does not serve to remove the obligation to disclose because in normative terms gender history is always likely to be considered a material fact. Moreover, if gender history were to be considered a material fact by the other party, then on Herring's view of consent, a sexual crime by 'fraud' would occur in the absence of disclosure. Moreover, he is not alone in this view. ${ }^{11}$ It might be objected that a transgender defendant would not be found guilty due to a lack of mens rea even if Herring's proposed definition of consent were to be legally adopted. However, under the Sexual Offences Act 2003 the prosecution need only show that the defendant lacked a 'reasonable belief' in consent. Again, in normative terms, it seems highly unlikely that a jury would consider a belief in consent to be reasonable in circumstances of non-disclosure.

We need to unpack Herring's claims further. It is, in the present context, far from clear that a right to sexual integrity ought to take precedence over a right to privacy. In the first place, the sexual integrity argument assumes an absence of consent. In turn, consent is presumed to be absent where gender history is considered to be a material fact by the party who lacks knowledge. Gender history ought not to be considered a material fact in legal terms. When a transgender woman stands before a man at a marriage ceremony the material fact is that she is a woman. This claim is legally as well as psychologically and anatomically, and probably biologically, ${ }^{12}$ accurate. Law ought not to go behind

9 ibid, 522-523 (emphasis added).

10 ibid, 523.

11 R. Williams, 'Deception, Mistake andVitiation of the Victim's Consent' (2008) 124 LQR 132-159, 149. The Law Commission have rejected such a conclusion and have noted its incompatibility with Article 8 of the European Convention on Human Rights (Law Commission, Consent in Sex Offences: A Policy Paper:Appendix C of Setting the Boundaries (London: Home Office, 2000, para 5.31).

12 Contemporary scientific studies conducted post mortem on transgender women suggest that they possess a female brain structure. Such studies support the hypothesis that gender identity develops as a result of an interaction of the developing brain and sex hormones (L. J. G Gooren, J. N. Zhou, 
this central legal fact in search of other 'facts.' The claim that a non-transgender person's right to sexual integrity should trump the privacy rights of transgender people appears to be based on certain normative assumptions, namely, that many, perhaps most, non-transgender people would choose not to have sexual intercourse with a transgender person if informed in advance of gender history. While these claims, which are implicit in the argument, appear to have no empirical basis, they can be rejected even if true. This is because the key material fact ought to be considered a transgender person's legally recognised gender status, ${ }^{13}$ not prejudice rooted in transphobia. If however, it were concluded that gender history is a material fact and that non-disclosure operates to vitiate consent, it is contended that a right to know based on a lack of consent ought to be trumped in this context by other material considerations.

While Herring appears willing to sacrifice the privacy rights of transgender people in favour of the right of others to sexual integrity, he fails to consider the sexual or bodily integrity of transgender people. In the present context, informational privacy bears down directly on facts about the body, its history and surgical alteration. This is something that Herring accords little, if any, weight. However, more significantly, the weighing of interests requires consideration of other factors. In particular, we might ask, should consent be viewed as vitiated where its apparent absence is premised on racism? Herring would appear to think so. ${ }^{14}$ Thus, according to the logic of Herring's argument, where a woman is anti-semitic and communicates her anti-semitism to her Jewish sexual partner, rape occurs if he has intercourse with her without disclosing his Jewishness. In other words, for Herring, Jewish status would be considered a material fact in these circumstances. But why should this be the case? It appears counterintuitive. The difficulty here is that Herring appears willing to allow a very broad definition of non-consent to trump a public policy concern over anti-semitism. In other words, Herring appears to want to privilege consent even where its apparent absence has its basis in racism. In short, if we are to take consent as seriously as Herring suggests, it appears that we must take prejudice seriously in equal measure. The consent argument here is a weak one and is not worthy

M. A. Hofman and D. F. Swaab, 'A Sex Difference in the Human Brain and its Relation to Transsexuality’ (1995) 378 Nature 68-70; F. P. M. Kruijver, J. N. Zhou, C. W. Pool, M. A. Hofman, L. J. G. Gooren and D.F. Swaab, 'Male-To-Female Transsexuals have Female Neuron Numbers in a Limbic Nucleus' (2000) 85 J Clin Endocr Metab 2034-2041; see also M. M. McCarthy, J. M. Schwarz, C. L. Wright and S. L. Dean, 'Mechanisms Mediating Oestradiol Modulation of the Developing Brain' (2008) 20 J Neuroendocrinol 777-783; M. M. McCarthy, C. L. Wright and J. M. Schwarz, 'Old Tricks by an Old Dogma: Mechanisms of the Organizational/Activational Hypothesis of Steroid-Mediated Sexual Differentiation of Brain and Behavior' (2009) 55 Horm Behav 655665; E. Govier, M. Diamond, C. Slade and T. Wolowiec, 'Dichotic Listening, Handedness, Brain Organization and Transsexuality’ (2010) 12 Intl J Transgenderism 144-154).

13 Emphasis on legal recognition is not inconsistent with a view of transgender identity as stable and long-standing. The legal stamping of gender as definitive does not ground ontological claims. Rather, it provides them with the imprimatur of law and makes the right to marry possible. Accordingly, once a GRC has been granted, which, of course, will always be the case in relation to the marriage issue under consideration, there is no longer any discrepancy between gender identity and legal gender status.

14 n 8 above, 523 . 
of defending when measured against the public policy interest in countering anti-semitism.

Interestingly, Williams distances herself from Herring regarding the Jewish example. ${ }^{15}$ Her hesitancy, when contrasted with her attitude toward transgender non-disclosure, is revealing. It is perhaps a distinction many people might make. This however, does not point to its correctness. Rather, it serves to highlight differential normative understandings brought to bear on questions of racism and transphobia ${ }^{16}$ respectively. Concern over sexual integrity in the context of the law of rape or marriage is as dubious in the transgender context as it is in the context of anti-semitism. Indeed, it could be argued that concern over sexual integrity is more dubious in the transgender context because the transgender person, unlike the Jewish man in the example, does not conceal his/her identity. It might be objected that equating transphobia with anti-semitism in this context only works if minding about gender history is as transphobic as minding about race is racist. This is precisely my argument. The fact that it provokes resistance reveals not the falseness of the argument but society's failure to take transphobia as seriously as it does racism. Alternatively, the reader might concede that transphobia is no less objectionable than racism but argue that, in the context of marriage, gender is more important than race and therefore the right to know is stronger in relation to gender. It is accepted that, in the context of marriage, gender is more important than race. What is rejected is the claim that the right to know about gender extends beyond the legal facts contained within a Gender Recognition Certificate (GRC). To argue the contrary is to suggest that a GRC is an unreliable indication of gender. ${ }^{17}$ This runs contrary to the spirit of the GRA and transgender law reform more generally. Moreover, this challenge to coherent gender identity serves to bolster the problematic notion that there is something of a yuk factor involved in sexual intercourse with transgender people. These are not normative ideas that law should support. Indeed, the fact that transphobia appears to be especially entrenched in our society, ${ }^{18}$ serves to strengthen a moral

15 n 11 above, 149.

16 'Transphobia is an emotional disgust toward individuals who do not conform to society's gender expectations ... The "phobia" suffix is used to imply an irrational fear or hatred, one that is at least partly perpetuated by cultural ideology' (D. Hill and B. Willoughby, 'The Development and Validation of the Genderism and Transphobia Scale' (2005) 53 Sex Roles 531-544, 91).

17 It might be suggested that the claim that a GRC is a reliable indication of gender does not sit well with the possibility of a transgender man becoming pregnant subsequent to a marriage. Indeed, this scenario has actually occurred in the USA http://www.guardian.co.uk/world/2008/nov/13/ gayrights-usa-thomas-beatie-pregnant (last visited 2 August 2011). A number of comments need to be made here. First, the fact that a transgender man, Thomas Beatie, became pregnant does not detract from his strongly felt sense of gender identity as a man. Given that his wife lacked reproductive capacity he chose to delay a hormonal process that would have rendered him sterile in order that the couple were able to become parents with at least some genetic link. This case might be used to support the claim of a right to know. However, given the facts that this case is a rare instance in another jurisdiction and that there is no evidence of any such occurrence in the UK, it would seem disproportionate, on this basis alone, to single out transgender people for special legal attention through the disclosure provision. Moreover, the decision to have a child in the Beatie case was made jointly by both Thomas Beatie and his wife. There was no deception of any kind.

18 S. Whittle, L. Turner and M. Al-Alami, The Equalities Review: Engendered Penalties: Transgender and Transsexual People's Experiences of Inequality \& Discrimination (London: Press for Change, 2007); J. 
obligation to communicate different and more appropriate norms. Further, if law proves reluctant to conclude that consent is vitiated in the Jewish 'rape by fraud' example, then legal consistency ought to require the same conclusion in the transgender context. If disclosure of gender history and disclosure of Jewish identity are materially different, then the obligation to demonstrate this lies with those who make this assertion. It has not been demonstrated and can only be so by a self-defeating argument that relies on prejudice against transgender people.

It is, of course, precisely this type of prejudice that explains the existence of the gender history ground. Without such normative understandings the provision would make no sense. The provision and arguments based on the right to know imply that a transgender woman is not really a woman and/or that sexual intercourse with her is not really heterosexual, or indeed lesbian in the context of a civil partnership. These suggestions are both offensive and contrary to the general tenor of the GRA. Thus the gender history ground for annulling a marriage or civil partnership not only places a legal obligation on transgender people to disclose facts that bear a highly personal and ontological character, it also serves to detract from the recognition that the GRA ostensibly confers. In other words, law's assertion that a transgender woman is legally a woman is undercut by the gesture law makes toward any party she might marry or with whom she might enter into a civil partnership. It would seem that, within the context of marriage, and through the gender history provision, the GRA constructs the 'truth' of sex as biological ${ }^{19}$ despite its apparent emphasis on a shift from sex to gender. ${ }^{20}$ Transgender, it would seem, and despite the GRAs attempt at normalisation, represents an excess, an unruly desire that threatens to problematise and engulf law's binary understanding of bodies and their desires. The assumption, implicit within the non-disclosure provision, that non-disclosure of gender history represents a form of harm, appears to be an effect of law's inability to suspend its disbelief about bodies it has otherwise incorporated within the social and legal order. This difficulty points to the transphobia and/or homophobia of law. It would appear that law continues to see homosexual relations or at least non-heterosexual relations even where they no longer exist according to its own formal logic. This legal anxiety is given shape and colour by case law as well as by the parliamentary debates surrounding the enactment of the GRA. Before turning to consider these particular expressions of anxiety, it is however, first necessary to deal with another potential objection that arises here.

Given the fact that there exists a degree of legal ambivalence concerning transgender status, it might be argued, especially to the extent that legal recognition is relied on to challenge the disclosure provision, that the GRA does not effect a full transformation in gender status. This argument would serve to contest the claim that present legal gender status is a reliable indication of gender. This,

Morton, Transgender Experiences in Scotland: Research Summary (Scottish Transgender Alliance: Edinburgh, 2008).

19 However, law's construction of sex here fails to take into account the growing scientific evidence pointing to a biological explanation for transgenderism (see n 12 above).

20 R. Sandland, 'Feminism and the Gender Recognition Act 2004' (2005) 13 Feminist Legal Studies 43-66. 
in turn, would support the claim of a right to know. There are however, difficulties with such an argument. First, while the gender history provision does reveal a degree of legal and political ambivalence concerning the gender status of transgender people, section 9(1) of the GRA clearly states that a GRC constitutes recognition for all legal purposes. To the extent that the gender history provision detracts from the the broader aims of the GRA it invites criticism. Rather than considering gender status to be incomplete, the better view is that legal conditions are imposed on fully recognised transgender men and women which encroach on their rights. The gender history provision does not challenge directly 'acquired' gender identity. Rather, it seeks to ensure that a prospective marriage partner is informed that this legal status has not always been possessed.There is no inconsistency here between legal gender status as stated in a GRC and the long-standing sense of gender identity many transgender people experience.

Second, the view that law has not effected a full transformation in gender status can be viewed as casting doubt on the authenticity of gender identity in the case of transgender people. In particular, there is a danger of pathologisation. This is especially so given that a diagnosis of gender dysphoria is the trigger for everything that happens under the GRA. However, while gender identity disorder is technically a mental illness, ${ }^{21}$ it serves in practice to name a feeling of incongruity between anatomy and gender identity thereby enabling medical professionals to determine in individual cases suitability for surgery and hormone administration. The mental illness model for comprehending transgender people has become increasingly suspect and it is a source of considerable dissensus within the World Professional Association of Transgender Health (WPATH). ${ }^{22}$ It seems likely that in time gender identity disorder will be declassified as a mental illness in much the same way that homosexuality was declassified as a mental illness by the American Psychiatric Association in $1973^{23}$ and by the World Health Organisation in $1992 .{ }^{24}$

In pursuing the theme of legal anxiety over the possibility of inadvertent sexual congress with transgender people, concern was expressed in the House of Commons about a transgender woman who 'had five lovers and did not tell any of them that she used to be a man. ${ }^{25}$ In relation to case law, in cases where disclosure of gender history has occurred the courts have given particular emphasis to this fact and it has served both as a source of judicial relief and as a factor

21 DSM-IV-TR: Diagnostic \& Statistical Manual of Mental Disorders (Arlington,VA: American Psychiatric Association Press, Inc, $4^{\text {th }}$ revised ed, 1994) s 302.85. For a critique of the mental illness model in relation to the GRA see S. Cowan, 'Gender is no Substitute for Sex: A Comparative Human Rights Analysis of the Legal Regulation of Sexual Identity’ (2005) 13(1) Feminist Legal Studies 67-96.

22 http://www.wpath.org (last visited 4 August 2011). Indeed, the WPATH 2011 Bi-annual Symposium is entitled 'Transgender Beyond Disorder: Identity, Community, and Health' (Atlanta, Georgia 24-28 September 2011). See also W. Bockting, 'Are Gender Identity Disorders Mental Disorders? Recommendations for Revision of the World Professional Association for Transgender Health's Standards of Care' (2009) 11(1) Intl J of Transgenderism 53-62.

23 R. Bayer, Homosexuality and American Psychiatry: The Politics of Diagnosis (Princeton, NJ: Princeton University Press, 1987.

24 The World Health Organisation removed homosexuality from its International Classification of Diseases (ICD-10) in 1992.

25 The Hon Andrew Selous, HC Deb 2 $2^{\text {nd }}$ Reading col 16611 March 2004. 
in moments of legal recognition. ${ }^{26}$ In cases where transgender individuals have not disclosed their gender history prior to marriage legal anxiety has proved to be especially evident. For example, in the New York contested marriage case of Anonymous v Anonymous ${ }^{27}$ the court noted that on the night of his wedding, the biologically male plaintiff soldier 'awoke at 2 o'clock in the morning, reached for the defendant [a pre-operative male to female transgender woman] and upon touching the defendant, discovered that the defendant had male sexual organs' at the sight of which ' $[\mathrm{h}] \mathrm{e}$ immediately left the bed' and 'got drunk some more, ${ }^{28}$ a scene vividly captured in Neil Jordan's film the Crying Game. ${ }^{29}$

In the English context, this judicial concern is most dramatically illustrated in the case of ST (formerly J) $\mathrm{v} J .{ }^{30}$ In this non-disclosure of gender history marriage case, the court noted that the effect of non-disclosure on a genetic wife, ST, who had stated that she "was not into women,'31 had been 'catastrophic and that she [had] been traumatised by the experience. ${ }^{32}$ We might wonder what precisely constitutes harm here. In particular, is it 'rooted in what the [complainant] actually experienced, or does the social conception of the type of relations that they experienced compel them to understand the experience as injury? ${ }^{33}$ If the latter, then law is revealed to be implicated in generating the very harm for which it punishes transgender people. The horror that the perception of (trans)sexual relations within marriage evokes is also apparent when contrasted with the extensive list of 'deceptions,' including the potentially harmful non-disclosure of HIV/AIDS, in relation to which Ward LJ expressed the view that, in contrast to the case of J, he 'would be very slow to allow an appeal to public policy striking out a claim for ancillary relief.'

This idea of transgender bodies, and particularly sexual congress with them, as evoking legal horror is an important one in understanding the gender history provision. The point becomes illuminated when we contrast law's treatment of transgender people with its treatment of intersex people. Intersex people are not legally required to disclose information about their gender history because the disclosure requirement only applies to those who marry by virtue of a GRC and the GRA does not apply to intersex people. Different treatment might seem strange given the existence of the provision and the concerns that animate it. Moreover, it is perhaps not unreasonable to suggest that some people might like to know that their intended marriage partner is intersex. It is contended that the explanation for this differential treatment lies in the legal deployment of a nature/artifice dyad. While both intersex and transgender people may undergo

26 See, for example, $M T$ v JT 355 A 2d 204 (1976), 205; Mv M [1991] NZFLR 337, 348; Re Kevin and Jennifer v Attorney-General for the Commonwealth of Australia [2001] FamCA 1074 at [39].

27325 NYS 2d 499 (1971).

28 ibid, 499.

29 B. Morkham, 'From Parody to Politics: Bodily Inscriptions and Performative Subversions in the Crying Game' (1995) 1 Critical in Queeries 47-68.

30 [1998] 1 All ER 431.

31 ibid, 439.

32 ibid, 456.

33 A. Gross, 'Gender Outlaws before the Law: the Courts of the Borderlands' (2009) 32 Harv J L and Gender 165-231, 199.

34 n 30 above, 466 . 
genital surgeries, in the case of intersex people, surgery is understood as assisting nature, whereas in the case of transgender people, surgery is understood as a departure from it. ${ }^{35}$ It is precisely in this 'unnatural' space that law constructs harm and an account of the 'truth' that challenges the authenticity of transgender people.

The legal anxiety referred to in this section of the article reveals much about legal and broader cultural understandings of transgender bodies, identities and desires and their imagined relationship to harm. Ultimately, the gender history provision, the normative understandings that underpin it and the forms of legal reasoning adopted to defend it, all serve to perpetuate a view of transgender people as a source of sexual danger, as ontologically unstable and as deceptive. In thinking of the gender history provision in terms of harm, it becomes clear that an emphasis on the right to know is not a step consistent with overall harm reduction. Rather, the provision perpetuates transphobia. In the next section we will see, that in addition to being harmful to transgender people, the provision is also discriminatory.

\section{THE GENDER HISTORY GROUND AS DISCRIMINATION}

The legal requirement to disclose gender history can be viewed as discriminatory. There are a number of reasons for this claim. First, the requirement to disclose historical facts is limited to gender. There are other grounds within section 12 of the MCA for annulling a marriage. However, only two pertain to non-disclosure of information: having a venereal disease and being pregnant. ${ }^{36}$ Importantly, only the gender history ground applies to a fixed identity group. ${ }^{37}$ Venereal disease and pregnancy are more appropriately viewed in legal terms as states of affairs. Further, it is only the gender history ground that relies for its operation on the fact of non-disclosure. In relation to venereal disease and pregnancy nullity proceedings can be initiated irrespective of knowledge, albeit that such proceedings may fall foul of the equitable bar if the petitioner was aware of the relevant facts. ${ }^{38}$ Accordingly, transgender people as a class, or at least those with a GRC wishing to marry, are singled out and are alone required to disclose historical 'facts.' Thus it is historical facts about (trans)gender that law seeks to have revealed.

There is no such requirement in relation to, for example, race, physical disability or sexuality. Thus a person is not, prior to marriage, required to disclose the fact that s/he used to identify as lesbian, gay or bisexual and/or that s/he has engaged in same gender sexual relations. Equally, in the context of a civil partnership ceremony, a person is not required to disclose the fact that $\mathrm{s} /$ he used to identify as heterosexual or bisexual or that $\mathrm{s} /$ he has engaged in opposite gender

35 A. Sharpe, 'English Transgender Law Reform and the Spectre of Corbett' (2002) 10(1) Feminist Legal Studies 65-89.

36 MCA, s $12(\mathrm{e})$ and (f).

37 Conversely, anybody might become infected with venereal disease and any woman with reproductive capacity might become pregnant. In other words, MCA, s 12(e) and (f) are concerned with facts the occurrence of which is contingent. There is nothing contingent about the fact of being transgender.

$38 \mathrm{MCA}, \mathrm{s} 13$. 
sexual relations. In the context of disability, a person who either is or was legally classified as disabled is not required to disclose this status prior to marriage. In a similar vein, a person is not required to disclose their racial background. Thus a person of mixed race might be presumed to be black or white. If the other party to the marriage is labouring under some kind of misapprehension concerning race or ethnicity, non-disclosure of racial or ethnic 'facts' produces no legal consequences. It is not clear why gender history is singled out for special treatment. Histories of, for example, race, sexuality and disability might be considered no less significant. They are histories that potential marriage partners may wish to know. It would seem that in marriage law, historical 'facts' pertaining to gender are considered more fundamental than other kinds of historical 'facts.'

The reader might think that a legal emphasis on gender is simply an effect of the gendered nature of the legal arrangements under consideration. That is to say, marriage is open only to parties of the opposite gender and civil partnership only to parties of the same gender. In contrast, facts about race, disability or sexuality are legally irrelevant to the formation of a valid marriage contract. This is, of course, legally correct, though it has not always been so in relation to race. ${ }^{39}$ However, it is important to remember that transgender persons who have been issued with a GRC have received legal recognition of their 'acquired' gender and are free to enter into the legal institutions of marriage or civil partnership. Non-disclosure of gender history does not serve to challenge the rules governing access to either form of spousal recognition. It does not render a marriage or civil partnership invalid. Rather, it enables accelerated exit from a lawfully binding agreement. Given these facts, it is less obvious why transgender people should be singled out for special treatment with regard to the issue of disclosure. In other words, while it is conceded that marriage is a gendered relationship, transgender persons in possession of a GRC are appropriately gendered in legal terms.

It might, nevertheless, be contended that transgender is different in some important way from race, sexuality and disability and that the difference justifies discriminatory treatment. In particular, there appear to be two distinct, though related, reasons for contending that transgender is materially different from race, sexuality and disability. First, it might, in the present context, be claimed that there has been a change of gender and that change is important to the question of disclosure. Second, it might be claimed that transgender can be distinguished from disability, race and sexuality on the basis of its greater invisibility. The first claim is overstated.The GRA does effect change at the level of legal classification of gender. However, in many, if not most, cases there is no change in terms of gender identity. Rather, gender identity remains constant. In this sense, legal recognition merely gives effect to what many transgender people have known since childhood.

Further, an argument emphasising change as a distinguishing consideration fails to recognise that race, sexuality and disability are not stable categories. All

39 Inter-racial marriage has been, and in some parts of the world continues to be, outlawed. In the US context, such marriages remained unlawful in 17 states as recently as 1967 (Loving v Virginia 388 US 1 (1967)). See P. Pascoe, What Comes Naturally: Miscegenation Law and the Making of Race in America (New York: OUP, 2009). 
three categories can be viewed as socially constructed rather than referring to definite or fixed groups of individuals living in the real world. These categories, like gender, are best described as contingent. Thus, and by way of example, disability is a legal category that can change either by way of expansion or contraction over time depending on the drawing of legal boundaries. Accordingly, it is possible for this status to be legally acquired or lost without any physical change occurring. Moreover, legal definitions do not necessarily accord with clinical or self-understandings of disability. ${ }^{40}$ In relation to race, the category has no proper scientific basis. Rather, it is an idea that has its origins in a racist and colonial past. ${ }^{41}$ As for sexuality, the categories of homosexuality and heterosexuality are nineteenth century sexological constructs. ${ }^{42}$ Their relationship to the sexual life-world can, as Queer theory contends, be viewed as reductive. ${ }^{43}$

Of course, race, sexuality and disability might be said to have relatively stable normative meanings. The important point however, is that these meanings are no more stable than those applicable to gender. The possibility of change exists across all these categories. Indeed, gender is not perhaps the category where change is most likely. The reader might object that, while gender change is no more likely than change in other respects, reliance on gender stability is more significant to a prosective marriage partner than the stability of race, sexuality or disability. This may be so, though it needs to be emphasised in the transgender context that instability should be understood in relation to legal, not ontological change. Moreover, this might be viewed as strengthening the claim of a right to know in the context of gender. However, and as already argued, the key material fact ought to be considered current gender status which has been brought into alignment with gender identity through the GRA. Knowledge of this fact ought to exhaust a right to know. If this argument is rejected a right to know gender history ought to be trumped by a public policy concern to limit transphobia.

The second claim, the claim of invisibility, assumes an ability and desire on the part of transgender people to 'pass' ${ }^{44}$ While many transgender people lack the ability to 'pass' successfully, it is evident that the non-disclosure provision aims

40 G. Albrecht and J. Levy, 'Constructing Disabilities as Social Problems' in G. Albrecht (ed), Cross National Rehabilitation Policies: A Sociological Perspective (London: Sage, 1981) 14.

41 The 'scientific' study of race commenced in the mid-eighteenth century with Carl von Linneaus' taxonomic study of human beings in Systema Naturae published in 1735 (see M. J. Anderson, Carl Linnaeus: Father of Classification (United States: Enslow Publishers, 1997); W. Blunt, Linnaeus: the Compleat Naturalist (London: Frances Lincoln, 2001); A. Polaszek, Systema Naturae 250 - The Linnaean Ark (Boca Raton, Florida: CRC Press, 2010). The view that racial categories are socially constructed and lack a biological basis has been reinforced by the advent of DNA (J. Marks, Human Biodiversity: Genes, Race, \& History (New York: Aldine de Gruyter, 1995)).

42 M. Foucault, The History of Sexuality: An Introduction (London: Penguin, R. Hurley trans, 1981); D. F. Greenberg, The Construction of Modern Homosexuality (Chicago, Illinois: Chicago University Press, 1988); J. Weeks, Against Nature: Essays on History, Sexuality and Identity (London: Rivers Oram, 1991).

43 J. Butler, Gender Trouble: Feminism and the Subversion of Identity (New York: Routledge, 1990); E. Sedgwick, The Epistemology of the Closet (New York: Penguin, 1990).

44 It should be recognised that 'passing' is controversial both as a practice and as an idea (see, for example, S. Stone, 'The Empire Strikes Back: A Posttranssexual Manifesto' in J. Epstein and K. Straub (eds), Body Guards: The Cultural Politics of Gender Ambiguity (London: Routledge, 1991) 280-304; Bornstein n 2 above; L. Feinberg, Trans Liberation: Beyond Pink or Blue (Boston: Beacon Press, 1998)). 
specifically to cover those who do. Indeed, it is the prospect of 'passing' that confers meaning on the provision. In other words, but for the possibility of 'passing' that which law demands be disclosed would already be in the open. Accordingly, it can be said that some transgender people and, more importantly, those to whom the provision is directed implicitly, are invisible in social terms. However, it is important here to be clear about what precisely it is that is invisible about some transgender people. What is typically not invisible is present gender role, gender identity and anatomical form all of which have received the imprimatur of the law through a GRC. Rather, what is invisible is the fact that a transgender person's legal status has changed. Gender identity has not typically changed. Rather, law has eventually recognised this fact and for all legal purposes. $^{45}$

In any event, it needs to be recognised that the other categories under consideration, namely disability, race and sexuality, do not lend themselves to total transparency. Thus many disabilities are not written on the surface of the body. They are not therefore necessarily visible to potential marriage partners. In other words, many disabled people 'pass' as able-bodied. In relation to the category of race, persons of mixed race may, for example, appear to be black or white. By the same token, many gay men 'pass' as straight in various social contexts. Homosexuality is not typically written on the body. The important point to note here is that 'passing' and therefore invisibility is not in any way unique to the lives of transgender people.

However, the main legal difficulty here is not that gender, as distinct from sexuality, race or disability, exhausts legal desire for historical knowledge. Rather, it is the fact that while gender is singled out it is not gender at large with which law is concerned. Rather, the legal obligation to disclose gender history applies only to transgender persons legally capable of marrying or entering into a civil partnership. That is to say, non-transgender women and men choosing to marry are not generally required to disclose personal facts that relate to their gender pasts. ${ }^{46}$ Thus, for example, non-transgender women and men are not required to disclose the fact that in childhood they were considered tomboys or sissies and perhaps enjoyed these gender roles. ${ }^{47}$ Rather, it is a particular kind of gender experience with which law is concerned.

Therefore it would seem that the gender history ground for annulling a marriage or civil partnership may contravene Article 14 of the European Convention on Human Rights. Article 14 states that the enjoyment of rights and freedoms set forth in the Convention 'shall be secured without discrimination on any ground such as sex, race, colour, language, religion, political or other opinion,

45 GRA, s 9(1).

46 The reason for the caveat is that contraction of a sexually transmitted disease and pregnancy occur within gender contexts. While these grounds for nullity (MCA, s 12(e) and (f)) do not depend on non-disclosure, disclosure will make application of the equitable bar more likely (s 13). In this sense, non-transgender people, and especially women, might be viewed as being incited by law to disclose facts that pertain to gender.

47 M. Rottnek, Sissies and Tomboys: Gender Nonconformity and Homosexual Childhood (New York: New York University Press, 1999); M. A. Abate, Tomboys: A Literary and Cultural History (Philadelphia: Temple University Press, 2009). 
national or social origin, association with a national minority, property, birth or other status.'While transgender is not specifically covered, the term 'sex' has been interpreted by the European Court of Justice to include transgender persons intending to undergo, undergoing or having undergone gender reassignment. ${ }^{48}$ Sex discrimination under Article 14 does not therefore cover transgender people who do not intend or who are unable to undergo gender reassignment surgery. ${ }^{49}$ In recognising the possibility of a discrimination claim under Article 14 it should be appreciated that Article 14 does not protect against discrimination at large. Rather, it provides protection only where discrimination encroaches on a specific right guaranteed under the Convention. The Convention rights undermined by the gender history ground of the MCA are the right to marry, guaranteed by Article 12, and the right to privacy, guaranteed by Article 8 . While the gender history ground does not preclude a lawful marriage from taking place, it constitutes direct discrimination under Article 12 because it treats the status of that marriage differently from other marriages in an unfavourable way on the ground of sex. The following section will consider how the gender history ground encroaches on the Convention right to privacy.

\section{THE GENDER HISTORY GROUND AS AN ENCROACHMENT ON THE RIGHT TO PRIVACY}

The legal requirement to disclose gender history requires the disclosure of highly personal and private information. Accordingly, it might be viewed as constituting a breach of Article 8 of the European Convention on Human Rights. According to Article 8 'everyone has the right to respect for his private and family life, his home and his correspondence.'The content of the phrase 'private and family life' has been interpreted widely. ${ }^{50}$ In $R$ (Wood) $\mathrm{v}$ Commissioner of Police of the Metropolis Laws LJ suggested that the core value protected by the right is 'the personal autonomy of every individual. ${ }^{51}$ The 'physical and psychological integrity' ${ }^{52}$ and the "physical and social identity" 53 of individuals have also been noted to fall squarely within the protection of the right. In particular, and for present purposes, Laws LJ highlighted that an individual's personal autonomy should make him 'master of all those facts about his own identity. ${ }^{54}$ In a similar vein, and in an

48 Pv S and Cornwall County Council Case C-13/94 [1996] ECR 1-2143. This interpretation of the law has been confirmed and extended in later case law of the European Court of Justice. See, for example, Sarah Margaret Richards v Secretary of State for Work and Pensions Case C-423/04 [2006] ECR $1-3585$.

49 It should be recognised that because legal recognition under the GRA does not depend on gender reassignment surgery, some transgender people choosing to marry will not be able to rely on Article 14. Accordingly, discrimination claims based on the gender history provision are likely to be more circumscribed than breach of privacy claims brought under Article 8.

50 See, for example, $X$ and $Y \mathrm{v}$ the Netherlands [1985] 8 EHRR 235 at [22]; Mikulic v Croatia [2002] 1 FCR 720 at [53]; Pretty v UK [2002] 35 EHRR 1 at [66]; $R$ (Wood) v Commissioner of Police of the Metropolis [2009] EWCA Civ 414 (Wood).

51 Wood ibid at [20].

52 Pretty v UK n 50 above at [50] perVon Hannover J; at [66] per Marper J.

53 ibid at [66] per Marper J.

54 n 50 above at [21]. 
earlier House of Lords decision, Lord Hoffmann noted that 'the law now focuses upon the protection of human autonomy and dignity' and that this includes 'the right to control the dissemination of information about one's private life. ${ }^{55}$ It is contended that historical facts concerning gender are deeply personal and private for many transgender people. A legal requirement to disclose gender history might therefore be viewed as contravening Article 8(1). Certainly, in the context of non-disclosure of gender history prior to sexual intercourse, the Law Commission have taken the view that to view this as rape by fraud would be incompatible with the state's Article 8 obligations. ${ }^{56}$

However, there are limits to the right to privacy. In Wood Laws LJ noted three qualifications. First, if Article 8 is to be engaged, 'the alleged threat or assault to the individual's personal autonomy must . . . attain "a certain level of seriousness." 57 It can hardly be suggested that compulsory disclosure of highly personal information pertaining to pre-transition gender history lacks seriousness. Second, enjoyment of the Article 8 right assumes that on the facts the claimant has 'a reasonable expectation of privacy. ${ }^{58}$ Again it seems clear that transgender people have a reasonable expectation of privacy regarding their pre-transition legal gender status. Indeed, the GRA emphasises this point through the creation of a criminal offence in circumstances where persons acting in official capacities disclose information concerning a person's gender history. ${ }^{59}$ The issue that arises here is whether the interest of the state and/or the other party to a marriage in knowing historical 'facts' concerning gender outweighs a transgender person's right to privacy. It is precisely this concern to balance interests that Laws LJ posits as his third qualification. ${ }^{60}$ Specifically, Article $8(2)$ provides states with an escape clause if they can show that breach of the right of privacy is justified on the basis of 'national security, public safety or the economic well-being of the country, for the prevention of disorder or crime, for the protection of health or morals, or for the protection of the rights and freedoms of others.'

If the state is to rely on Article 8(2) as justification for the nullification of a marriage on the basis of non-disclosure of gender history, it is 'the protection of the rights and freedoms of others' that would be the most appropriate part of Article 8(2) to assert. In relation to the rights of others, the court in Goodwin v $U K$ made clear that a fair balance has 'to be struck between the general interest of the community and the interests of the individual. ${ }^{61}$ It is contended that to conclude that the interests of others, the community and/or the state outweigh the interests of transgender people in this context would, in order to be convincing, require a demonstration that non-disclosure of gender history constitutes some form of harm. It is precisely the possibility of harm that would create the right Article 8(2) is designed to protect. Moreover, without the possibility of consequential harm it is difficult to see how a right to know the gender history

55 Campbell v MGN Ltd [2004] 2 AC 457 at [51].

56 n 11 above.

57 n 50 above at [22].

58 ibid.

59 GRA, s 22.

60 n 50 above at [22].

61 (2002) 35 EHRR 18 at [72]. 
of a marriage partner could arise or, at least, be legitimately defended. This claim of harm is one already considered and rejected.

Moreover, in balancing the interests of transgender people against those of the state it is important to recognise that the issue of non-disclosure of gender history has not, so far as I am aware, actually led to nullity proceedings under section 12(h) of the MCA. Further, the incidence of such proceedings is likely to be very low. This is because the number of transgender people with a GRC, and who are therefore able to marry, is miniscule. ${ }^{62}$ Of that number only a proportion will want to marry. Of that portion only a very small number 'pass' successfully enough to make disclosure an issue in practical terms. Others will choose to disclose to intimates. What we are left with is a tiny number of people who might be in a position not to disclose and who choose not to do so. Even if nondisclosure were to be viewed as harmful, the gender history provision appears in these circumstances to be an overwhelmingly disproportionate response to perceived harm. Accordingly, it is contended that the state cannot rely on Article 8(2) in order to justify its encroachment on the privacy rights of transgender people. Any attempt to do so is unlikely to strike a chord with the European Court of Human Rights if challenged. In the next section, the article will refute the idea that there is something necessarily fraudulent or deceitful about non-disclosure of gender history. This idea of fraud or deceit, which precedes the GRA ${ }^{63}$ as well as being embedded within it through the introduction of the gender history ground, is, as we will see, one which again points to a legal failure to incorporate transgender people fully within the normative legal order.

\section{THE ETHICS OF NON-DISCLOSURE OF GENDER HISTORY}

In this section it will be argued that non-disclosure of gender history is not unethical, or at least not necessarily so. However, before proceeding to develop this argument it should be recognised that objection to the gender history provision does not depend on the ethical status of non-disclosure. As we saw earlier, the non-disclosure provision is both discriminatory and encroaches on the right to privacy. Further, if the reader concludes that non-disclosure of gender history is unethical it does not follow that such behaviour should be subjected to legal regulation. There is no necessary connection between law and immorality. ${ }^{64}$ It certainly does not follow that transgender people should be singled out for special legal attention. Further, the burden of establishing the claim that nondisclosure is unethical rests squarely with the party who asserts it. This is, perhaps, especially so given the individualistic focus of contemporary culture and law and the lack of any credible evidence of sufficient harm arising from non-disclosure to justify the provision. It is contended that distress, disgust and/or revulsion are

62 The most recent available figures published by the Gender Recognition Panel are for August 2010. At this time 2,605 GRCs had been issued. For more information see the Gender Identity Research and Education Society website at http://www.gires.org.uk/grp.php (last visited 17 July 2011).

63 n 26,27 and 30 above.

64 H. L. A. Hart, The Concept of Law (Oxford: Clarendon Press, 1961). 
inadequate forms of harm to justify state intervention against a minority group. ${ }^{65}$ To warrant serious consideration harm would need to be more substantial. In determining rules by which to live it is at least as important for an individual to consider the psychological, emotional and ontological risks of disclosure, as it is to consider distress rooted in transphobia. The fact that a high degree of openness might be seen as ideal within marriage does not on its own serve to qualify this point.

Turning to the ethical question, implicit in the creation of the gender history ground is the view that non-disclosure of gender history is deceitful, that it represents some type of interpersonal fraud. This claim is disingenuous in at least two ways. First, it is important to recognise that there are different ways of not telling the 'truth.' These differences, it is contended, bear on the question of whether non-disclosure ought to be regarded as deceitful, and therefore on the question of whether an obligation to disclose gender history ought to exist. Second, the gender history ground assumes or suggests that the paramount truth about gender status resides not in the present but in the past. In this sense, failure to reveal the past is presented as inconsistent with the truth and therefore as ethically suspect. In this regard, and as already noted, the gender history provision proves inconsistent with the GRA as a whole as well as contrary to transgender law reform generally given that reform has sought to incorporate transgender people within the normative legal order. In this latter regard, the issue might be viewed as being less about transgender deceit and more about the inauthenticity of law given law's inability to commit fully to its own claims. What must be contested here is precisely the manner in which 'truth' is legally constituted. What is at stake is the ontological significance for many transgender people of past 'facts' that law demands be recounted.

Let us turn to these two arguments and sets of concerns. First, there are at least three ways of not telling the truth - deliberately lying, actively misleading and misleadingly withholding information. ${ }^{66}$ It is contended that deliberately lying and actively misleading another are more morally problematic than merely withholding information. Some scholars have argued that mere non-disclosure of self to others is tantamount to fraud or deceit. ${ }^{67}$ However, as Schoeman observes, provided that 'a person does not misrepresent himself to those who, within the relevant domain, reasonably rely on his projected image, that person is not acting deceptively. ${ }^{68}$ I hesitate to describe the withholding of information here as 'misleading' in anticipation of the second argument that will contest the notion that particular constructions of fact, in relation to which misleading might be said to occur, are accurate.

Withholding information is to restrict its flow. It is to keep things secret. Yet secrecy is not the same thing as deception. As Bok notes: '[t]o confuse secrecy and

65 Mill, $n 7$ above.

66 S. Wilkinson, 'Why Lying is Worse than Merely Misleading' (2000) 13 Philos Today 6-7.

67 R. Wasserstrom, 'Privacy: Some Arguments and Assumptions' in R. Bronaugh (ed), Philosophical Law (Westport, Conn: Greenwood Press, 1978); R. Posner,'The Right to Privacy' (1978) 12 Georgia L Rev 393-422.

68 F. D. Schoeman, 'Privacy and Intimate Information' in F. D. Schoeman (ed), Philosophical Dimensions of Privacy: An Anthology (London: Cambridge University Press, 1984) 403, 409. 
deception is easy, since all deception does involve keeping something secret . . But while all deception requires secrecy, all secrecy is not meant to deceive. ${ }^{69}$ More significantly perhaps, is the fact that secrecy is central, indeed indispensable, to human well-being. We must consider 'the drawbacks of too much information as well as those of being kept in the dark. ${ }^{70}$ Indeed, others have argued that privacy is essential to the formation of relationships, including those of love and friendship. For relationships between self and others are based on an individual's ability to share and control personal information. ${ }^{71}$ In defence of some control over secrecy and openness, Bok notes four different elements of human autonomy: identity, plans, action and property. ${ }^{72}$ In relation to personal identity, she contends, secrecy guards its central aspects. ${ }^{73}$ Indeed, for Bok, "without perceiving some sacredness in human identity, individuals are out of touch with the depth they might feel in themselves and respond to in others. ${ }^{74}$ She argues for "partial individual control over the degree of secrecy or openness about personal matters - those most indisputably in the private realm. ${ }^{75}$

It would be extremely difficult to argue that gender history does not fall within this ambit of autonomy. It is perhaps difficult to specify the most appropriate analogy here. Secrecy, or perhaps we should say the maintenance of privacy, in relation to gender history might be compared to the control of information exhibited by some victims of child abuse.Yet, we would not demand that a victim of child abuse disclose details of the abuse or even the fact of abuse within the context of an intimate, including a marriage, relationship. The reader might respond that this is because (a) an intimate partner would remain unaffected by this piece of personal information and (b) it would be intolerable to demand disclosure in these circumstances. In relation to (b) the point is sound. In relation to (a) however, it is far from clear that an intimate partner would remain unaffected over the course of a relationship. A history of child abuse might make its presence felt in numerous ways. ${ }^{76}$ In pursuing this analogy it might be viewed as equally intolerable that transgender people should be required to disclose deeply personal information about their pasts. Like some victims of child abuse, some transgender people choose and feel able to disclose information about their pasts within intimate settings. However, for others, their chromosomal status, their earlier gonadal and/or genital condition, as well as the gendered pattern of socialisation to which they were subjected as children and young persons is a source of pain and trauma.

Turning to the second argument it is important to recognise, despite the foregoing discussion concerning the withholding of information and its moral

69 S. Bok, Secrets: On the Ethics of Concealment and Revelation (Vintage Books: London, 1998) 7.

70 ibid 18.

71 C. Fried, 'Privacy: A Moral Analysis' in Schoeman (ed), n 68 above 203; J. Rachels, 'Why Privacy is Important' in Schoeman (ed), ibid 290.

72 n 69 above 20 .

73 ibid 13.

74 ibid 21

75 ibid 27.

76 K. R. Berenson and S. M. Andersen, 'Childhood Physical and Emotional Abuse by a Parent: Transference Effects in Adult Interpersonal Relationships’ (2006) 33 Pers Soc Psychol B 1509. 
implications, that the 'facts' which ought to be disclosed, or which might legitimately be kept secret, are not agreed. To be more precise, contestation exists around whether the 'facts' law demands be recounted are factually true. Thus the gender history provision appears to require that a transgender woman, for example, disclose the 'fact' that she has not always been a woman. But what does this mean? Obviously, she has not always enjoyed this legal status. However, she may have always had a clear sense of female gender identity, seeing herself first as a girl and later a woman. Moreover, the notion that transgender is reducible to psychological factors that can be readily trumped by biological 'facts' that reside in the past, a notion implicit in the creation of the gender history ground, is becoming increasingly suspect in scientific terms. There is growing scientific evidence pointing to a biological account for transgenderism. ${ }^{77}$ Accordingly, the disclosure requirement, at least in some cases, may be viewed as amounting to no more than a requirement to disclose information about an initial, and incorrect, legal classification as well as a history of coerced gender performance. It is hard to conclude in these circumstances that a decision to control personal information, and in the process retain some sense of personal autonomy, is in any significant sense unethical.

\section{CONCLUSION}

This article has considered a specific legal obligation imposed on transgender people who intend to marry or enter into a civil partnership. By virtue of the MCA, as amended by the GRA, transgender people living in the UK are, prior to going through a marriage ceremony, expected to disclose information about their gender pasts. Failure to do so enables the other party to exit the marriage in an accelerated fashion. This legislative provision is objectionable in a number of respects. First, it is discriminatory, and therefore contrary to Article 14 of the European Convention on Human Rights, in that it targets transgender people as a class in a way that encroaches upon their Article 8 and 12 rights. There is no corresponding legal obligation placed on non-transgender people to disclose information about gender history. Second, it represents an encroachment upon the right to privacy guaranteed by Article 8 of the Convention, one that is not easily justified within the ambit of Article 8(2). Third, the logic of a contrary finding would involve a conclusion that sexual contact with transgender people is potentially harmful. This is a view that should not be given any legal oxygen in normative terms. It is a view that runs contrary to the spirit of transgender law reform and indeed the GRA itself. Further, the assumption of harm is premised on the claim that gender history is a material fact. This claim has been rejected. However, if gender history were to be considered a material fact, either in some general normative sense or from the perspective of the other marriage party, this should not serve to vitiate consent because a right to know in these circumstances ought to be trumped by considerations of justice, legal consistency and a public policy concern to limit transphobia.

77 Gooren et al, n 12 above; Kruijver et al, n 12 above; McCarthy et al, 2008 and 2009, n 12 above; Govier et al, n 12 above. 
Finally, the article has sought to resist the legal and wider cultural tendency to view non-disclosure of gender history as an unethical omission. In opposition to this view, it was emphasised that secrecy does not equate with deception. On the contrary, secrecy is an essential adjunct to the private life. Moreover, the exercise of secrecy in relation to facts that bear a highly personal character is the very essence of personal autonomy and therefore the very essence of the set of rights protected by Article 8. In addition to this objection to the characterisation of transgender secrecy as deception, there is the further concern that this type of analysis concedes too much. That is to say, it is not simply a case of past 'facts' that ought to be disclosed, or over which privacy might be legitimately exercised. Rather, given the nature of transgenderism, the past 'facts' in question are not necessarily agreed, or indeed experienced. 